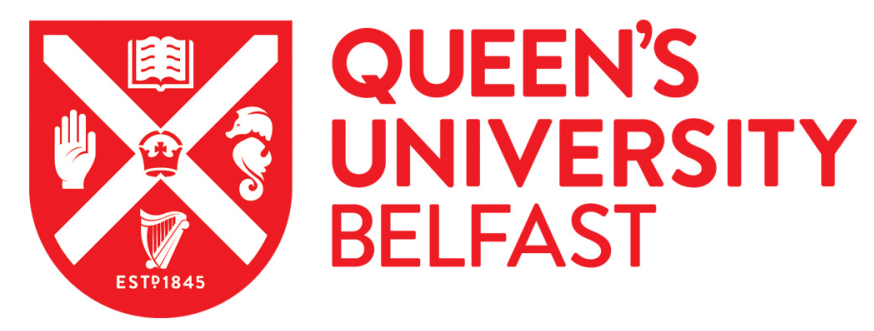

\title{
Super tough graphene oxide reinforced polyetheretherketone for potential hard tissue repair applications
}

He, M., Guo, Z., Qiu, X., Yang, Y., Su, C., Li, Y., Li, Y., Sun, D., \& Zhang, L. (2019). Super tough graphene oxide reinforced polyetheretherketone for potential hard tissue repair applications. Composites Science and Technology, 174, 194-201. https://doi.org/10.1016/j.compscitech.2019.02.028

Published in:

Composites Science and Technology

Document Version:

Peer reviewed version

Queen's University Belfast - Research Portal:

Link to publication record in Queen's University Belfast Research Portal

Publisher rights

Copyright 2018 Elsevier.

This manuscript is distributed under a Creative Commons Attribution-NonCommercial-NoDerivs License

(https://creativecommons.org/licenses/by-nc-nd/4.0/), which permits distribution and reproduction for non-commercial purposes, provided the author and source are cited.

\section{General rights}

Copyright for the publications made accessible via the Queen's University Belfast Research Portal is retained by the author(s) and / or other copyright owners and it is a condition of accessing these publications that users recognise and abide by the legal requirements associated with these rights.

Take down policy

The Research Portal is Queen's institutional repository that provides access to Queen's research output. Every effort has been made to ensure that content in the Research Portal does not infringe any person's rights, or applicable UK laws. If you discover content in the Research Portal that you believe breaches copyright or violates any law, please contact openaccess@qub.ac.uk. 


\section{Super tough graphene oxide reinforced polyetheretherketone for}

\section{hard tissue repair}

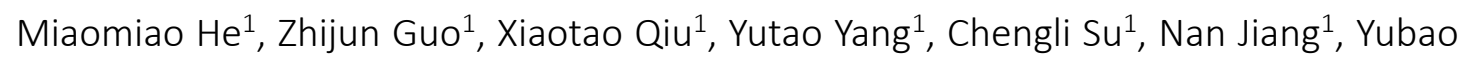

$\mathrm{Li}^{1}$, Dan Sun ${ }^{2 *}$, Li Zhang ${ }^{1 *}$

1. Analytical \& Testing Center, State Key Laboratory of Oral Diseases \& West China Hospital of Stomatology, Sichuan University, Chengdu 610065, China

2. Advanced Composite Research Group, School of Mechanical and Aerospace Engineering, Queen's University Belfast, Belfast, BT9 5AH, UK.

* Corresponding author

E-mail address: zhangli9111@126.com; nic1976@scu.edu.cn (Li Zhang) d.sun@qub.ac.uk (Dan Sun)

Abstract: Biocompatible polyetheretherketone (PEEK) is a favorable material for hard tissue repair due to its similar elastic modulus to that of the human bone. In this work, graphene oxide $(\mathrm{GO})$ reinforced PEEK nanocomposites with different GO loading have been prepared by injection molding. Mechanical testing reveals that the toughness of the reinforced composite varies with the GO loading, with $0.5 \%$ GO giving the greatest elongation at break (86.32\% greater than pristine PEEK). The underlying toughening mechanism has been attributed to the well-dispersed GO forming $\pi$ - $\pi^{*}$ conjugations at the GO / PEEK interface. These conjugations also acted as the nucleation sites for oriented crystallized region in PEEK. As the GO content increases further (e.g > 0.5\%), the fillers tend to agglomerate and would disturb the crystallites of PEEK and serve as stress concentration sites, resulting in decreased toughness. The biocompatibility of the composites has been evaluated in vitro, and the results showed that the addition of GO into PEEK favors the adhesion and spreading of bone marrow stromal stem cells, demonstrating the strong potential of our GO reinforced PEEK composites in applications such as hard tissue repair and replacement.

Keywords: polyetheretherketone (PEEK), graphene-oxide, reinforcement, conjugation, 
toughness.

\section{Introduction}

People are living longer nowadays due to better living conditions and advanced healthcare / medical technology. [1]. However, the aging population (in particular $>65$ years old) are at a high risk of developing degenerative disc disease, low bone density, and osteoarthritis. This, in addition to the increasing cases of sports injuries and road accidents, has led to greater demand for orthopedic implants, the market of which is expected to reach USD 47.7 billion by 2026 [2]. Titanium (Ti) and its alloys are widely used for orthopedic implants because of their excellent long-term biocompatibility [35]. However, their excessive elastic modulus ( $>100 \mathrm{GPa})$ often results in stress shielding effect, which would lead to high incidence of aseptic loosening of the implants [3]. Although Ti alloys with lower elastic modulus have been developed in recent years ( 80 GPa) [6], their mechanical property is still much higher than that of the human cortical bone and spongy bone (3 17 GPa) [7].

PEEK, a member of polyaryletherketone (PAEK) family, is a linear semicrystalline polymer composed of single repeating units in which two ether bonds and one ketone bond are linked by a benzene ring[8]. Its toughness originates from ether bonds and the rigidity from benzene rings. Owing to its unique structures, PEEK shows desirable mechanical properties similar to that of the human bone (elastic modules 3 17 GPa), in addition to its ease of processing and high resistance to cyclic stress. Furthermore, the anti-radiation property of PEEK enables its application in X-ray diagnosis in clinical settings $[9,10]$. At present, PEEK based products such as artificial 
spine, knee joint and skull etc. [11-16] are widely reported and some of them have been successfully trialed in clinical settings [17].

Graphene oxide (GO), one of the graphene derivatives, is a two-dimensional (2D) sheet with a structure of $s p^{2}$-hybridized carbon atoms packed into a honeycomb lattice [18]. While retaining the unique structure and properties of graphene, GO is rich in hydrophilic oxygen-rich groups (e.g - OH, -C-O- and - $\mathrm{COOH}$ ) [19], which favor cell adhesion and spreading and contribute to its biocompatibility [20]. Owing to its excellent mechanical properties, GO has also been used to reinforce various polymeric materials (such as epoxy [21], polyamide 6 [22]) for enhancing their tensile strength [23], stiffness [21] and toughness [22, 24].

The use of GO nanosheets for the modification of PEEK properties has only emerged recently. Table 1 summarized some of the recent studies dealing with material systems consist of PEEK and GO.

Table 1. Recent studies on composite systems consist of PEEK and GO.

\begin{tabular}{|c|c|c|c|c|c|c|c|}
\hline Matrix & Fillers & $\begin{array}{c}\text { Fabrication } \\
\text { methods }\end{array}$ & $\begin{array}{c}\text { Stain at } \\
\text { break }\end{array}$ & $\begin{array}{l}\text { Key material } \\
\text { functionality }\end{array}$ & $\begin{array}{l}\text { Interfacial } \\
\text { interaction }\end{array}$ & $\begin{array}{c}\text { Targeted } \\
\text { application }\end{array}$ & References \\
\hline $\begin{array}{l}\text { Sulfonated } \\
\text { PEEK/PVA }\end{array}$ & GO & Electrospinning & $<0.04$ & $\begin{array}{c}\text { Enhanced proton } \\
\text { conductivity }\end{array}$ & $\begin{array}{l}\text { Hydrogen bonding } \\
\text { between sulfonated } \\
\text { PEEK and GO }\end{array}$ & $\begin{array}{c}\text { Proton } \\
\text { exchange } \\
\text { membrane }\end{array}$ & [26] \\
\hline $\begin{array}{l}\text { Sulfonated } \\
\text { PEEK }\end{array}$ & GO & $\begin{array}{l}\text { Dry phase- } \\
\text { inversion } \\
\text { method }\end{array}$ & $<0.05$ & $\begin{array}{c}\text { Enhanced proton } \\
\text { conductivity }\end{array}$ & Not specified & $\begin{array}{c}\text { Proton } \\
\text { exchange } \\
\text { membrane }\end{array}$ & [27] \\
\hline PEEK & $\begin{array}{c}\mathrm{SiO}_{2} \text { and } \mathrm{GO} \\
\text { (APTES } \\
\text { modified) }\end{array}$ & $\begin{array}{l}\text { Melt blending } \\
\text { and injection } \\
\text { molding }\end{array}$ & $0.37 \sim 0.40$ & $\begin{array}{c}\text { Reduced coefficient } \\
\text { of friction and wear } \\
\text { rate }\end{array}$ & Not specified & $\begin{array}{c}\text { Tribological } \\
\text { contacts }\end{array}$ & [28] \\
\hline PEEK & $\begin{array}{c}\text { oxidized } \\
\text { MWNTs; } \\
\text { GO nanosheets; } \\
\text { or GO-Si } \\
\text { nanosheets }\end{array}$ & Molding & $\begin{array}{c}\text { Not } \\
\text { specified }\end{array}$ & $\begin{array}{c}\text { Reduced coefficient } \\
\text { of friction and wear } \\
\text { rate }\end{array}$ & $\begin{array}{l}\text { Chain entanglement } \\
\text { and chemical } \\
\text { bonding between } \\
\text { the grafting DB-551 } \\
\text { and matrix resin }\end{array}$ & $\begin{array}{c}\text { Tribological } \\
\text { contacts }\end{array}$ & [29] \\
\hline PEEK & $\begin{array}{l}\text { Ethyl-aminated } \\
\text { or phenyl- } \\
\text { aminated } \\
\text { GO/MWCNT }\end{array}$ & Hot-pressing & $\begin{array}{c}\text { Not } \\
\text { specified }\end{array}$ & $\begin{array}{c}\text { Enhanced thermal } \\
\text { conductivity }\end{array}$ & $\begin{array}{l}\text { Covalently bonded } \\
\text { by amide bonding }\end{array}$ & $\begin{array}{c}\text { Thermal } \\
\text { interface } \\
\text { applications }\end{array}$ & [30] \\
\hline
\end{tabular}


Filler dispersion / distribution and their interfacial interaction with the polymer matrix play a key role in the resulting composite mechanical properties [25, 26]. As is shown in Table 1, many researchers have surface functionalized the fillers in order to enhance their dispersion and/or enable stronger filler/matrix interfacial bonding to facilitate load transfer. However, this could also confine the motion of interfacial polymer segments. This is why the enhancements of composite stiffness, tensile strength and hardness of polymer are usually accompanied by a lower elongation at break and decreased ductility [27]. In addition, the use of potentially harsh / hazardous solvents and chemical agents to functionalize filler materials may present challenges to the in vivo applications of the composites in biomedical and healthcare field.

In the presence study, GO enhanced PEEK composites were fabricated by injection molding technology and the effect of GO loading on the properties of the resulting composite has been investigated thoroughly using universal mechanical testing machine, SEM, TEM, Raman, XPS and TG-DSC. The interaction mechanism between GO and PEEK has been elucidated in detail and the biocompatibility of the resulting composites has been evaluated in vitro. To the best of our knowledge, this is the first time injection molded composites consisting of pristine GO nanosheets and PEEK were produced with desirable mechanical and biological properties suitable for hard tissue implant applications. 


\section{Materials and methods}

2.1. Materials and preparation

Polyetheretherketone (PEEK) powder (Jilin Joinature Polymer Co., Ltd., China) was dried at $80^{\circ} \mathrm{C}$ in oven for $12 \mathrm{~h}$ before use. Graphene-oxide (GO) nanosheets ( 5 layers) with average radial size $\sim 2 \mu \mathrm{m}$ were provided by the Sixth Element (Changzhou) Materials Technology Co., Ltd. Injection molding was deployed to prepare coupons with different geometries complying with relevant mechanical testing standards (see Table 2, Fig 1 a-c).

Table 2. Referenced mechanical testing standards.

\begin{tabular}{lll}
\hline Group/shape & Testing & Standards \\
\hline Rectangular & Flexural test (Fig 1a) & GB/T 9341-2008/ISO 178:2001 \\
Square & Compressive test (Fig 1b) & GB/T 1041-2008/ISO 604:2002 \\
Dumbbell & Tensile test (Fig 1c) & GB/T 1040.1-2006/ISO 527-1:1993 \\
\hline
\end{tabular}

PEEK powder with different GO loading were first mixed with pure ethanol (1g mixed powder per $10 \mathrm{ml}$ ethanol) under magnetic stirring for 30 min under room temperature. The mixed PEEK and GO were then extracted through vacuum filtration and dried in oven at $60{ }^{\circ} \mathrm{C}$ until no further weight loss. Five types of composites were prepared according to the GO loading ( $n \mathrm{GO} \%$, where $n$ denotes the weight fraction of GO within the composite, see Fig 1d), and the samples were named as $n$ GO-PEEK. The dried mixed powder was then processed by a twin screw extruder (SJZS-10A mini conical twin screw extruder, Ruiming Plastics Machinery Manufacturing Company, 
Hanyang District, Wuhan) at a screw speed of $40 \mathrm{r} / \mathrm{min}$. The temperature profile of the barrel were $345^{\circ} \mathrm{C} / 345^{\circ} \mathrm{C} / 365^{\circ} \mathrm{C} / 367^{\circ} \mathrm{C}$ from the hopper to the die. The polymer melt was injected into metal moulds with a specific geometries (SZS-20 mini-injection machine. Ruiming Plastics Machinery Manufacturing Company). The final coupons were obtained by annealing at $200{ }^{\circ} \mathrm{C}$ for 2 hours before cooling down to room temperature.

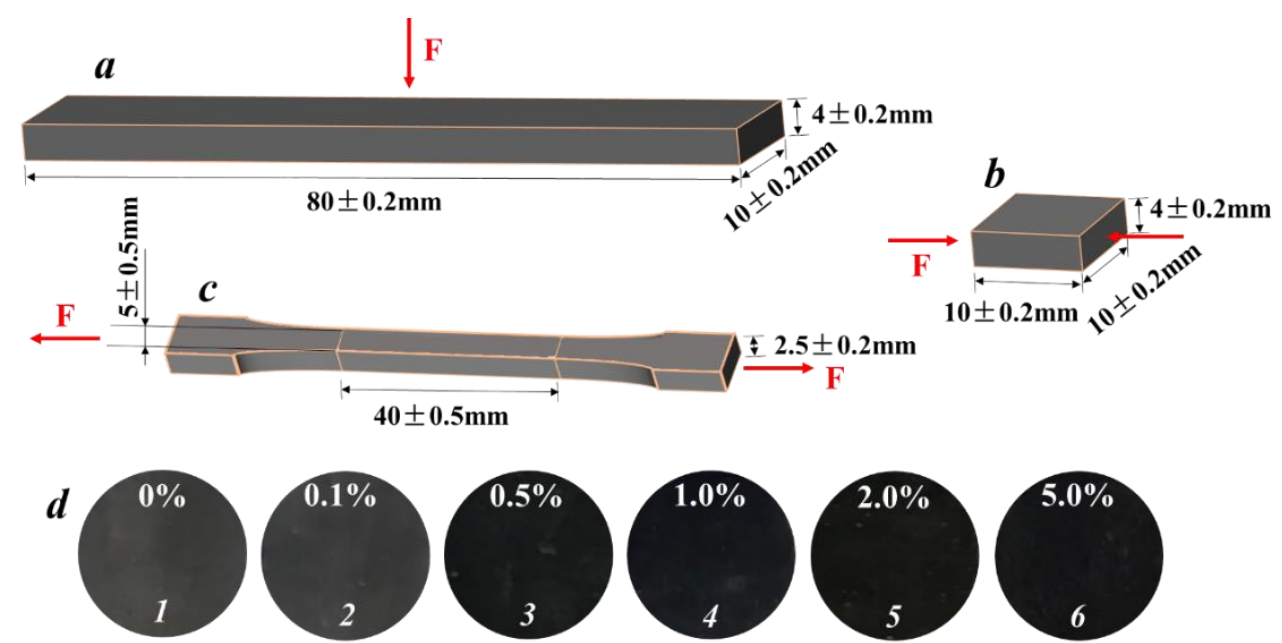

Fig 1. The geometry of coupons for (a) flexural testing, (b) Compressive testing and (c) Tensile testing, respectively; (d) Optical images showing composites with different $n \mathrm{GO} \%$.

\subsection{Characterization}

\subsubsection{Physical and chemical properties}

Tensile, compressive and flexural testing were performed using universal mechanical testing machine (MTS, model E45, America). The speed was set as 10 $\mathrm{mm} / \mathrm{min}$ for testing tensile properties and $4 \mathrm{~mm} / \mathrm{min}$ for compressive and flexural properties.

Morphologies of the tensile fractured sample cross-sectional surface were analyzed using scanning electron microscope (SEM, JSM-6510LV, Jeol, Japan) and the 
microstructure of $0.5 \mathrm{GO}-\mathrm{PEEK}$ was further observed by transmission electron microscope (TEM, Tecnai G2 F20 S-TWIN, FEI, America). The crystallinities of all coupons were studied by X-ray diffraction (XRD, DX-2500, China) and the samples were further analyzed by Laser Confocal Raman spectrometer (Invia, Renishaw, England). The chemical composition of the composite was investigated using X-ray photoelectron spectroscopy (XPS, XSAM800, Kratos, England). The thermal properties of the composites were measured using thermogravimetric analysis (TGA) and differential scanning calorimetry (DSC), using thermal analysis system (TGA/DSC2, Switzerland) under a $\mathrm{N}_{2}$ atmosphere. The temperature range is $25^{\circ} \mathrm{C}$ to $1500{ }^{\circ} \mathrm{C}$ and the heating rate is $20^{\circ} \mathrm{C} / \mathrm{min}$.

\subsubsection{In vitro analysis}

The biological properties of composites were evaluated by cell co-culture experiment on disc samples (diameter $=8 \mathrm{~mm}$, thickness $=1 \mathrm{~mm}$ ) for $1 \mathrm{~d}$. Bone marrow stromal stem cells (BMSCs) in the 3rd passage from three days SD rats was chosen for the study. The cells were incubated in Dulbecco's modified Eagle's medium (DMEM, Gibco, Canada) supplemented with $10 \%$ fetal bovine serum (FBS, Gibco, Canada) and $1 \%$ penicillin and streptomycin (Thermal scientific, USA). The cells were cultured on the surface of the samples in 48 -well plates incubated at $37{ }^{\circ} \mathrm{C}$ with $5 \% \mathrm{CO}_{2}$. Then the cells were fixed with $2.5 \%$ glutaraldehyde for $2 \mathrm{~h}$, dehydrated with graded concentration ethanol series (99\%), and gold sputtered for SEM observation.

The attached cells were observed using confocal laser scanning microscopy (CLSM, OLYMPUS, Japan). After $40 \mathrm{~h}$ of culturing on the specimens, the cells were 
fixed with $4 \%$ paraformaldehyde for 20 min and permeabilized with $0.1 \%$ Trion X-100 in PBS for 5 min. Then the cells were stained with FITC-phalloidin (Solarbio, China) for 30 min at room temperature, washed with PBS, and stained with DAPI (Solarbio, China) for 5 min. Finally, cell proliferation on the samples was investigated using Cell Counting Kit-8 (CCK8, CK04, Dojindo, Japan) after culturing for 1, 3 and 7 days.

\section{Results and discussion}

\subsection{Physical and chemical properties}

Fig 2a shows the stress-strain curves from the compression tests and the maximum compressive strength of the composites is over $120 \mathrm{MPa}$. The compressive modulus (Fig 2b) of all samples is in the range of 2,200-2,500 MPa, similar to that of the natural cancellous bone $(1,500 \sim 2,500 \mathrm{MPa})[28,29]$. It is also noted that, 2.0GO-PEEK and 5.0GO-PEEK showed significant decrease in compressive modules in comparison to pristine PEEK (12.49\% and $11.12 \%$ deduction, respectively).

The flexural strength of the GO/PEEK composites peaked at $\sim 160 \mathrm{MPa}$ for $0.5 \% \mathrm{GO}$ and $1.0 \% \mathrm{GO}$ (Fig 2c), and their corresponding flexural modulus is over 3,000 MPa (Fig 2d). It can be seen that although 2.0 and 5.0GO-PEEK exhibited similar or even better flexural modulus compareing to other GO-PEEK composites, they are more prone to fracture at a much lower strain level $\left(\varepsilon_{\mathrm{f}}=0.071\right.$ and 0.069 , respectively $)$. 

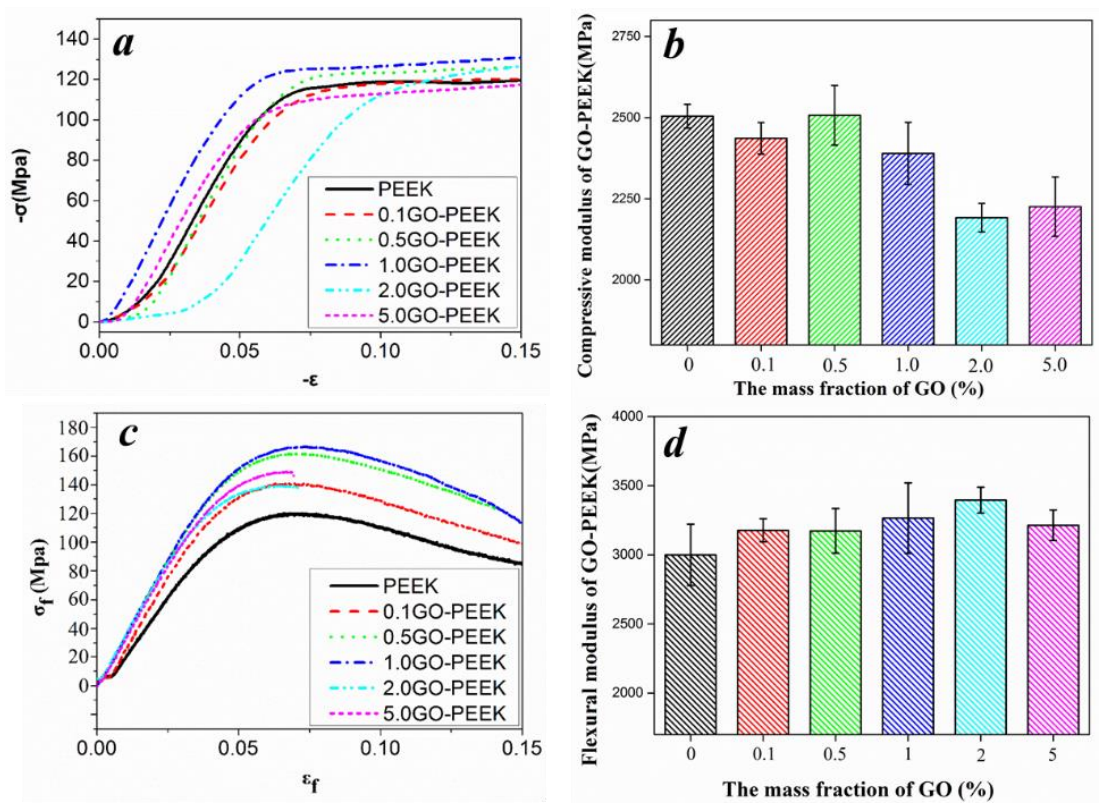

Fig 2. (a) The stress-strain curves of GO-PEEK composite from compressive test; (b) Compressive modulus ( $n=8$ ); (c) The stress-strain curves from flexural tests and (d) Flexural modulus $(n=8)$ of GO-PEEK composites.

The ultimate tensile strength of all samples are in the region of 100-110 MPa (see

Fig 3a). The tensile modulus of all GO-PEEK composites is approximately 1,300 MPa as presented in Fig $\mathbf{3 b}$. This is about $200 \mathrm{MPa}$ higher than the GO-carbon nanotube hybrid fillers enhanced PEEK reported previously[30], indicating the more superior stiffness of our composites [31, 32]. According to Fig 3c, the strain at break of the composites varies significantly with different GO content. The strain at break for most composites were greater than that of the pristine PEEK, with the exception of 5.0GOPEEK (12.14\% lower than pristine PEEK). The strain at break is the greatest for $0.5 \%$ GO-PEEK ( $86.32 \%$ greater than PEEK), much higher than the previously reported for $\mathrm{PEEK} / \mathrm{SiO}_{2} / \mathrm{GO}$ composites (44.41\% greater than PEEK) [33]. The ability of our material to absorb the energy up to fracture was calculated following the established procedure [34], and results have been listed in Table 3. Both Fig 3 and Table 3 show 
that $0.5 \mathrm{GO}-\mathrm{PEEK}$ demonstrated unprecedented toughness properties $(127.20 \%$ greater absorption energy than pristine PEEK), far superior than any other GO containing PEEK composite systems reported so far. The toughness of 0.5GO-PEEK also exceeds many other PEEK composites reinforced with different filler materials such as HA [35], $\mathrm{SiO}_{2}[36]$ and glass fibers [37].
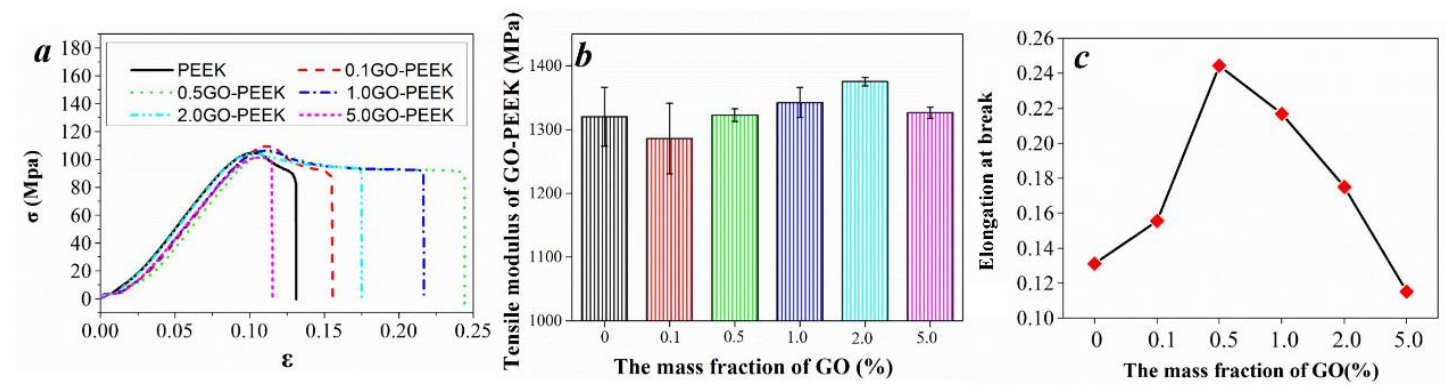

Fig 3. (a) Stress-strain curves for tensile tests; (b) tensile modulus $(n=8)$ and (c) The trend of strain at break for GO-PEEK composites.

Table 3. The energy absorbed up to fracture for composites with different $n \mathrm{GO} \%$.

\begin{tabular}{ccccccc}
\hline $\mathrm{nGO} \%$ & 0 & $0.1 \%$ & $0.5 \%$ & $1.0 \%$ & $2.0 \%$ & $5.0 \%$ \\
\hline Energy $\left(10^{3} \mathrm{KJ} / \mathrm{m}^{3}\right)$ & 7.50 & 9.37 & 17.04 & 15.01 & 11.69 & 5.62 \\
\hline
\end{tabular}

To investigate the fracture mechanisms of the GO-PEEK composites, the morphology of tensile fractured sample surface was analyzed, see Fig 4. The fractured surface of 0.5GO-PEEK and 1.0GO-PEEK features ductile fracture (severe elongation of materials), whereas the 2.0GO-PEEK and 5.0GO-PEEK fractured surfaces are typical of brittle fracture. 

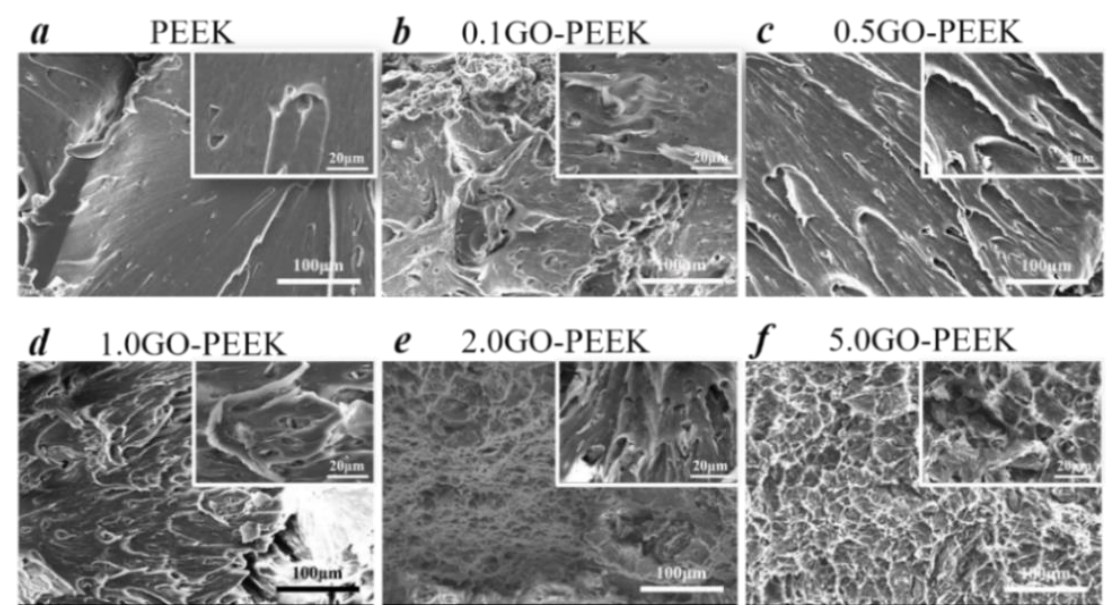

Fig 4. Cross-sectional SEM images of tensile fractured surfaces of GO-PEEK composites. Inset: corresponding higher magnification images.

The effects of $n \mathrm{GO} \%$ on the crystallinity of GO-PEEK composites were studied by XRD (Fig $\mathbf{5} \boldsymbol{a}$ ) and the intensity of the characteristic peak $2 \theta=18^{\circ}$ for all samples were listed in Table 4. 0.5GO-PEEK shows the greatest $2 \theta=18^{\circ}$ intensity amongst all samples (2331.89 a.u). Furthermore, the intensity ratio of the $2 \theta=18^{\circ}$ peak to $2 \theta=22^{\circ}$ peak is 1.51 for $0.5 \mathrm{GO}-\mathrm{PEEK}$ and 1.37 for pristine PEEK, respectively, indicating that $2 \theta=18^{\circ}$ is the preferred orientation for molecular alignment in $0.5 \mathrm{GO}-\mathrm{PEEK}$.

The DSC curves of heating (Fig 5b) and cooling (Fig 5c) of the GO-PEEK composites were recorded, and the melting temperature $(\mathrm{T} m)$, the crystallization temperature $(\mathrm{T} c)$ and the percentage of crystallization $(\mathrm{Xc} \%)$ are shown in Table 4 . The $\mathrm{Xc} \%$ was calculated following Equation (1) [38]:

$$
\mathrm{Xc} \%=\frac{\Delta H}{\Delta H_{m}^{0}} \times 100 \%
$$

The Tm for all samples is almost constant $\left(\sim 339^{\circ} \mathrm{C}\right)$, indicating the addition of GO has no distinct effect on the polymer melting point. The Tc of composites with GO content $>0.5 \%$, starts to show a decreasing trend, due to the impeding effect of the GO 
on the PEEK mobility [39]. On the other hand, as $n \mathrm{GO} \%$ increases from $0.1 \%$ to $5.0 \%$, Xc \% first peaked at $42.09 \%$ and dropped gradually to $23.20 \%$, i.e., a similar level to that of pristine PEEK (23.16\%). This indicates $0.1 \% \mathrm{GO}$ has the strongest nucleation effect that promote the formation of microcrystalline zones within the composite [40], whereas further increasing $n \mathrm{GO} \%$ would lead to the formation of more imperfect crystals [33].

It should be noted that PEEK, as a semi-crystalline polymer, consists of both crystalline and amorphous regions. A lower Xc\% can be associated with the greater mobility of polymer segments within the amorphous region, which contributes to the enhancement of polymer toughness [21,27]. In contrast to 0.1GO-PEEK, 0.5GO-PEEK demonstrated much reduced Xc\% but enhanced XRD $2 \theta=18^{\circ}$ peak intensity, indicating, the formation of a lower quantity but more oriented microcrystalline zones.

On the other hand, according to the flexural stress-strain curves, the composites are prone to fracture when $n \mathrm{GO} \%>2.0 \%$. At higher concentration the fillers tend to agglomerate and act as inclusions that facilitate the voids nucleation around them during plastic deformation. Under such condition, the fillers actually serve as stress concentration sites that facilitate the crack initiation and propagation, compromising the overall composite structural integrity and reduced the energy dissipation ability of the composites [41].

Table 4. The characteristic XRD peak intensity, melting temperature $(\mathrm{Tm})$, crystallization temperature (Tc) and Xc\% of PEEK and GO-PEEK.

\begin{tabular}{ccccc}
\hline Sample & $\begin{array}{c}\text { Intensity of } 2 \theta=18^{\circ} \\
\text { (a.u.) }\end{array}$ & $\operatorname{Tm}\left({ }^{\circ} \mathrm{C}\right)$ & $\mathrm{Tc}\left({ }^{\circ} \mathrm{C}\right)$ & $\mathrm{Xc} \%$ \\
\hline
\end{tabular}




\begin{tabular}{|c|c|c|c|c|}
\hline \multicolumn{4}{|c|}{ in XRD patterns } & \multirow[b]{2}{*}{23.16} \\
\hline PEEK & 1749.59 & 339.24 & 295.31 & \\
\hline 0.1GO-PEEK & 1224.46 & 337.60 & 295.62 & 42.09 \\
\hline 0.5GO-PEEK & 2331.89 & 339.95 & 292.19 & 30.26 \\
\hline 1.0GO-PEEK & 1958.04 & 339.86 & 290.20 & 25.93 \\
\hline 2.0GO-PEEK & 1927.20 & 339.41 & 289.93 & 27.95 \\
\hline 5.0GO-PEEK & 1945.78 & 339.93 & 290.45 & 23.20 \\
\hline
\end{tabular}

Given 0.5GO-PEEK demonstrating the best toughness amongst all samples, it was chosen for further thermal analysis and compared with pristine PEEK, see Fig 5d and Fig 5e. Both pristine PEEK and 0.5GO-PEEK have a melting point around $334^{\circ} \mathrm{C}$ and exhibit a two-step decomposition. The first degradation stage can be attributed to the dehydrogenation and decomposition of polymer segments [42, 43], the weight loss is about $45.35 \mathrm{wt} \%$ for $0.5 \mathrm{GO}-\mathrm{PEEK}, 3 \%$ lower than that for pristine PEEK. The second degradation process is the result of the carbonization (such as benzene rings in the polymer chain), and the weight loss of 0.5GO-PEEK about $9.30 \mathrm{wt} \%, 13.3 \%$ lower than that of PEEK. The DSC results indicate that 0.5GO-PEEK displays a better thermostability. It could be attributed to strong interaction between the PEEK and GO, which hindered the motion of polymer chains and restricted mobility of PEEK chains near filler [33]. 

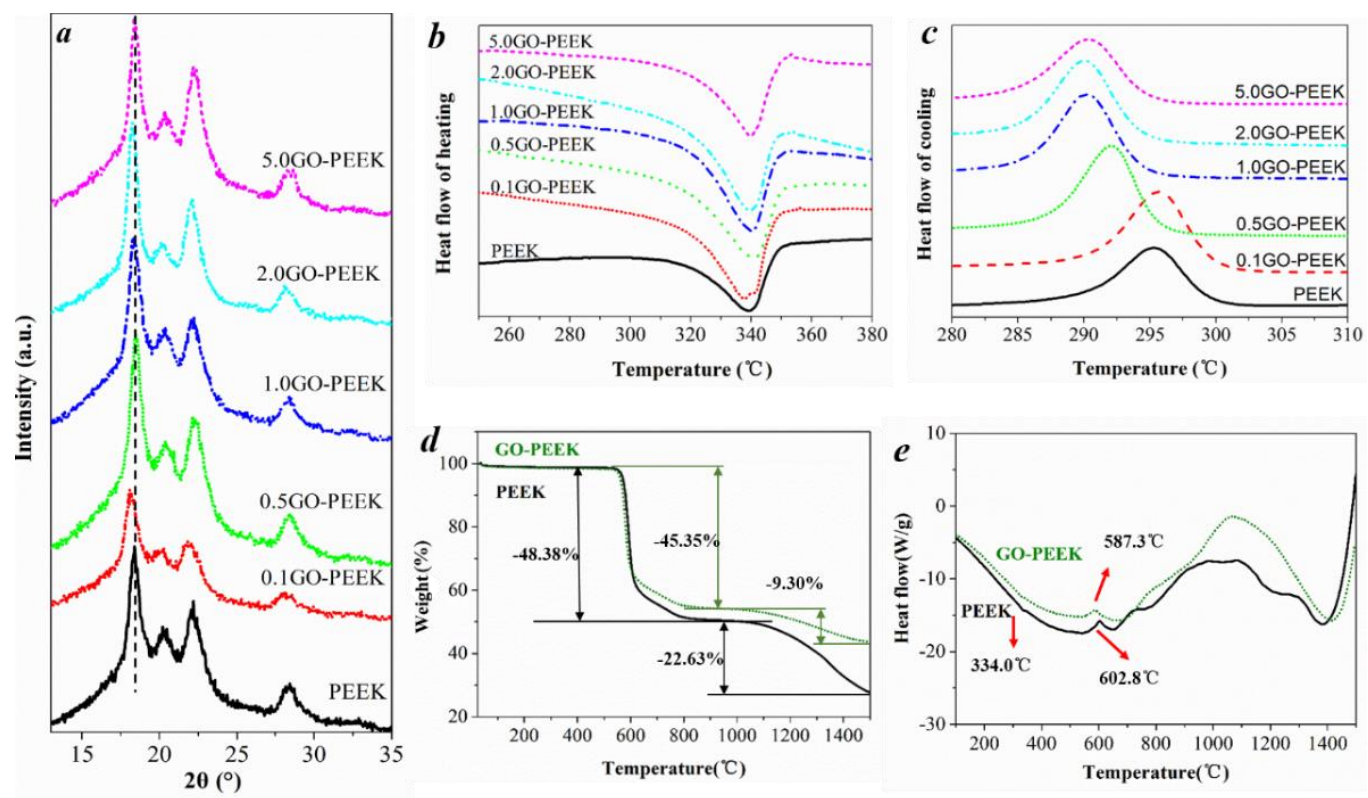

Fig 5. (a) XRD patterns; The DSC curves of (b) heating and (e) cooling GOPEEK composites; ( $f$ ) TG curves and (g) DSC curves of PEEK and 0.5GOPEEK from $25^{\circ} \mathrm{C}$ to $1400^{\circ} \mathrm{C}$.

Fig 6a-b show the typical TEM images of 0.5GO-PEEK. The contours of the embedded GO nanosheets are clearly visible, indicating the GO has retained its 2D structure, which may play a role in impeding crack propagation and enhance the toughness of the composites [35]. The states of carbon and oxygen in 0.5GO-PEEK were revealed by XPS spectra in Fig 6c. The signal of C-C/C-H bond at $284.60 \mathrm{eV}, \mathrm{C}-$ $\mathrm{O}$ bond at $286.20 \mathrm{eV}$ and $\mathrm{C}=\mathrm{O}$ bond at $289.30 \mathrm{eV}$ are evident in Fig 6d [44, 45]. Other characteristic peaks associated with oxygen containing groups are shown in Fig 6e, where $531.20 \mathrm{eV}$ is attributed to $\mathrm{O}=\mathrm{C}$ and $533.20 \mathrm{eV}$ to $\mathrm{O}-\mathrm{C}$ [46]. Laser confocal Raman spectra of PEEK and GO-PEEK are presented in Fig 6f. Since the G band of GO is at $1595 \mathrm{~cm}^{-1}$ and that of the benzene ring is at $1600 \mathrm{~cm}^{-1}[35,47,48]$, it is hard to distinguish between the two. However, it is noteworthy that the intensity of the characteristic peak is the greatest for 0.5GO-PEEK, which may be due to GO resulting 
in stronger polarizability of the crystal field [49].
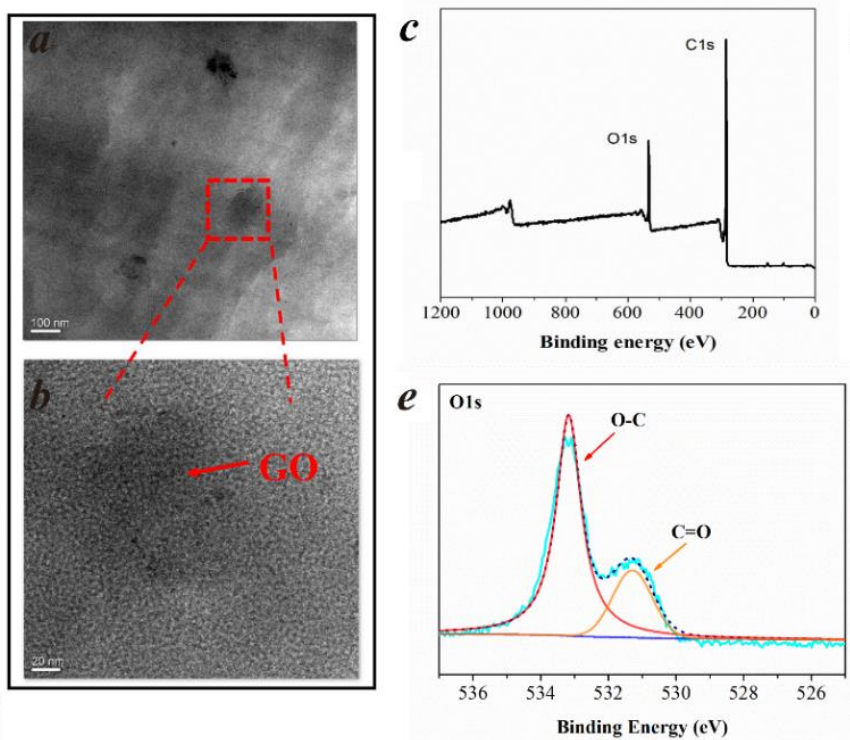
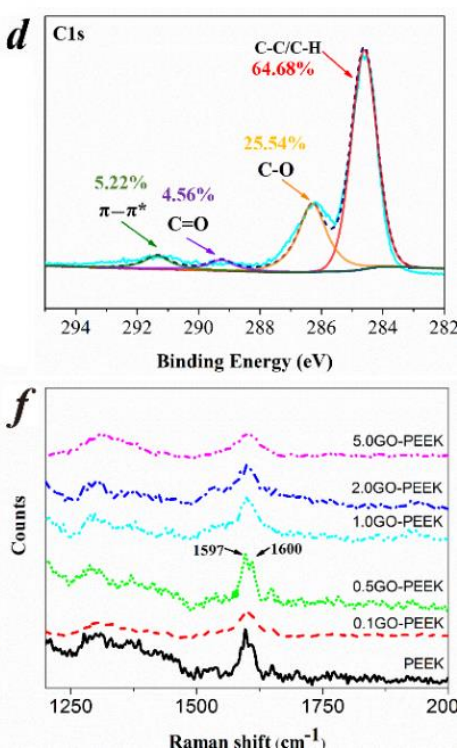

Fig 6. TEM images of 0.5GO-PEEK at (a) low and (b) high resolution; (c) XPS spectrum; deconvolution of (d) C1s and (e) O1s peak (f) Laser confocal Raman spectra of PEEK and GO-PEEK composites.

It is noteworthy that while $\pi-\pi^{*}$ bond $(291.40 \mathrm{eV})$ is absent from pristine PEEK $[50,51]$, it is clearly visible for all GO-PEEK composites, see Fig $6 \mathbf{d}$. This suggests the formation of $\pi-\pi^{*}$ conjugated structure and the strong interaction between GO and PEEK.

The benzene ring in PEEK is a carbon ring that consists of six $s p^{2}$ hybridized carbon atoms forming a plane hexagon, $\pi$ electron is present in the perpendicular direction in the six-membered ring [52]. The angle between adjacent carbon atoms is $120^{\circ}$ and the bond length is $1.4 \AA$. The angle and bond length of the six-membered carbon ring in GO resembles that of the benzene ring [53], where each carbon atom contributes an unbonded electron in the $p$ orbit, which could form a $\pi$ bond in the perpendicular direction to the plane [54]. Additionally, the $p$ orbit could form large polyatomic bonds throughout the whole layer like benzene rings [55]. The similarity in 
the structures of PEEK and GO allows for their strong interaction by means of $\pi-\pi^{*}$ conjugation. Since semi-crystalline PEEK would go through crystallization process during processing, GO which interacts with PEEK by $\pi$ - $\pi^{*}$ conjugation plays an active role as nucleating agents and accelerates the local crystallization of PEEK molecular chains and facilitate the adjacent polymer chains to extend along the GO plane to form microcrystalline area (See schematic in Fig 7). This correlates well with the increased $\mathrm{Xc} \%$ seen in GO containing composites as compared to pristine PEEK.

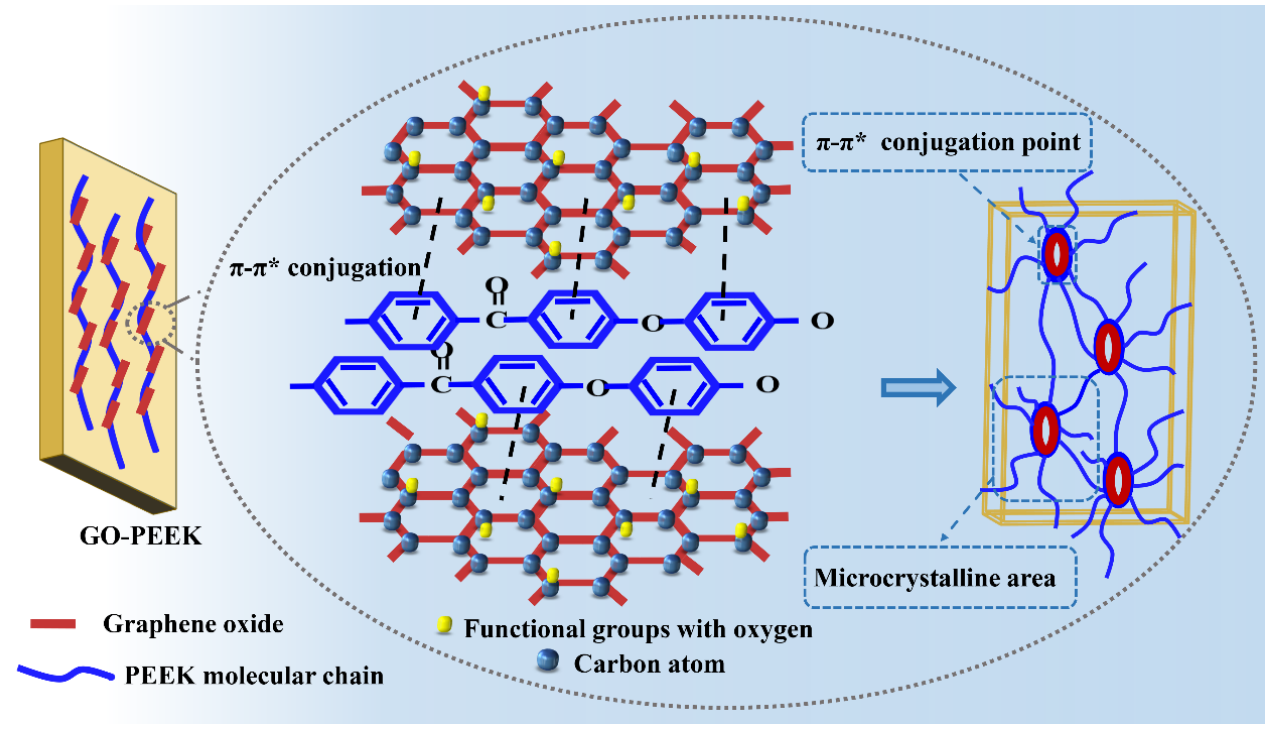

Fig 7. Schematic of the interaction mechanism between PEEK and GO.

\subsection{In vitro biocompatibility analysis}

Cell adhesion on the composite surface was studied to evaluate the biocompatibility of the composites. Fig 8a showed the morphologies of cells on the composite surfaces after culturing for 1 day. The BMSCs on PEEK, 2.0GO-PEEK and 5.0GO-PEEK show spherical morpholgy with less pseudopodia, while on 0.1GOPEEK, 0.5GO-PEEK and 1.0GO-PEEK, BMSCs spread much better with strong pseudopodia attachment on the surfaces in all directions, suggesting these samples are 
more favorable for cell adhesion (hence better biocompatibility) compared to other groups.

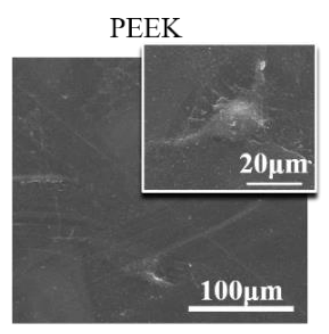

1.0GO-PEEK

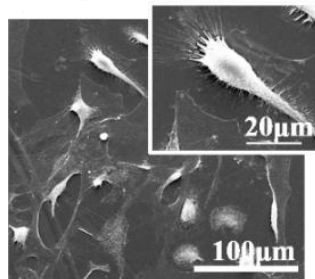

0.1GO-PEEK

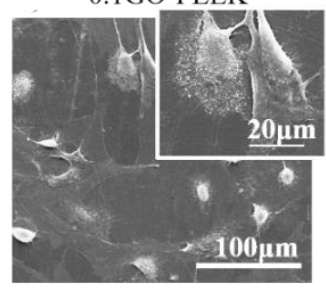

2.0GO-PEEK

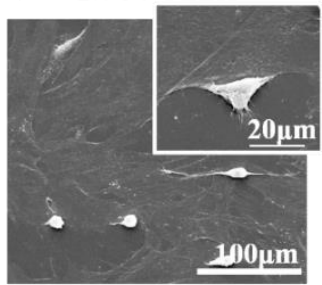

0.5GO-PEEK

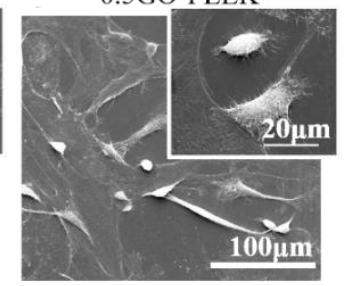

5.0GO-PEEK

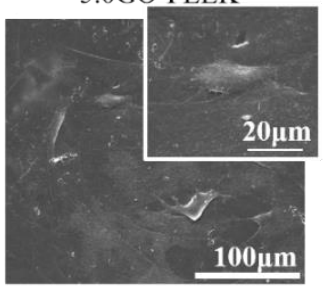

Fig 8. SEM images of BMSCs attached on the samples for 1 day.

Fig 9a shows the CLSM images of BMSCs after seeding for $40 \mathrm{~h}$. The morphologies of the fluorescence-stained BMSCs on different samples suggest that GO-PEEK composites allow better cell adhesion and spreading than pristine PEEK, with no obvious cytotoxicity. Fig $\mathbf{9 b}$ shows the results of CCK8, it can be seen that the BMSCs multiply on all sample surfaces after cultured for 1 day. The clear tendency of increased intensity over time (3 and 7 days) suggests the non-cytotoxicity for both pristine PEEK and GO-PEEK composites.
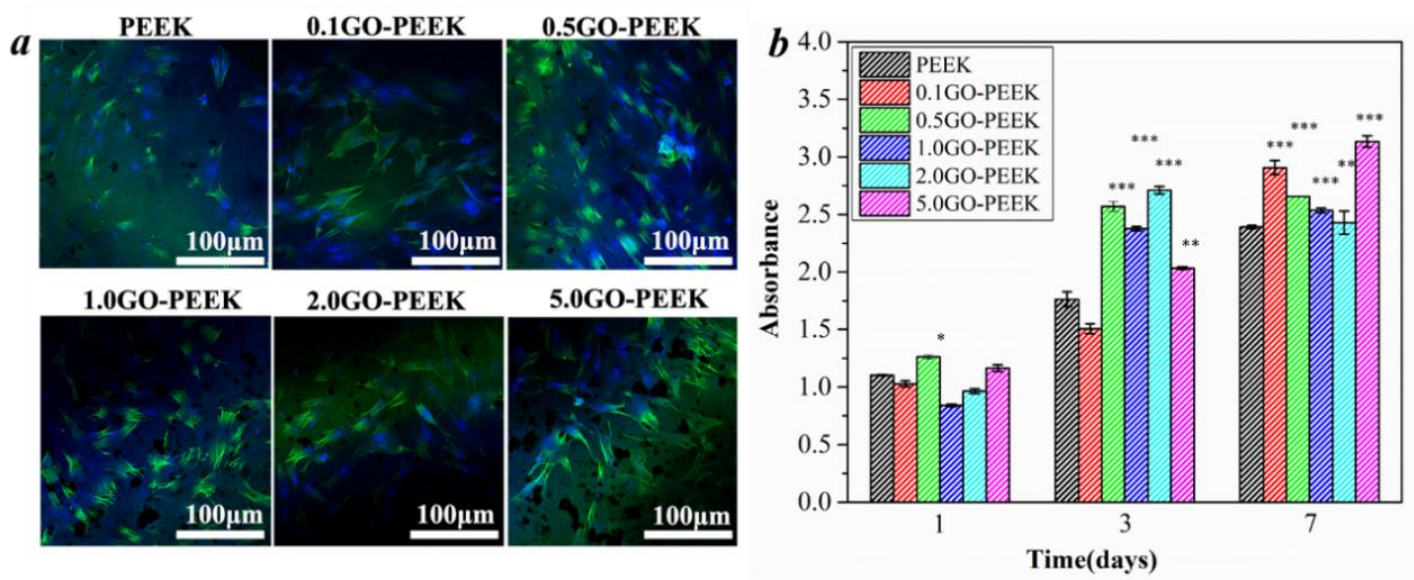
Fig 9. (a) CLSM images of BMSCs cultured for $40 \mathrm{~h}$; (b) the results of CCK8 of the samples: ${ }^{* \star *} p<0.001,{ }^{* *} p<0.01,{ }^{*} p<0.05$ vs PEEK under the same time.

\section{Conclusion}

GO-PEEK composites with varying $n \mathrm{GO} \%$ have been produced by injection molding technique. Experimental results show that the mechanical properties of the composites can be tuned by $n \mathrm{GO} \% .0 .5 \% \mathrm{GO}-\mathrm{PEEK}$ demonstrated superior toughness (86.32\% greater strain at break and $127.20 \%$ greater absorption energy, comparing to pristine PEEK). The great toughness enhancement has been attributed to the good dispersion of GO, strong interfacial interaction (formation of $\pi-\pi^{*}$ conjugation) between GO and PEEK, and the increased molecular chain alignment along the GO plane. In vitro biological study confirms that GO-PEEK composites have excellent initial cell adhesion ability and non-cytotoxicity. This study provides a promising strategy towards fabrication of PEEK-based composites with excellent biomechanical properties suitable for future hard tissue repair applications.

\section{Acknowledgements}

This work was funded by the National Natural Science Foundation of China (51673131, 31670965, 81801848), National Key Research and Development Program of China (2016YFA0201703/2016YFA0201700), International Collaborative Research Foundation of Sichuan Province (2018HH0068). We also present our thankfulness to the TEM (Yong Luo) and XPS (Suilin Liu) groups of Analytical \& Testing Centre, Sichuan University for their help.

\section{References:}

[1] A.R. Amini, C.T. Laurencin, S.P. Nukavarapu, Bone Tissue Engineering: Recent Advances and Challenges, Critical reviews in biomedical engineering 40(5) (2012) 363-408.

[2] G.V. Research, Orthopedic Device Market Worth \$47.7 Billion By 2026 (2018). 
[3] N. Jiang, Z. Guo, D. Sun, Y. Li, Y. Yang, C. Chen, L. Zhang, S. Zhu, Promoting Osseointegration of Ti Implants through Micro/Nanoscaled Hierarchical Ti Phosphate/Ti Oxide Hybrid Coating, ACS Nano 12(8) (2018) 7883-7891.

[4] Z. Guo, N. Jiang, C. Chen, S. Zhu, L. Zhang, Y. Li, Surface bioactivation through the nanostructured layer on titanium modified by facile HPT treatment, Sci Rep-UK 7(1) (2017) 4155.

[5] Z. Guo, C. Chen, Q. Gao, Y. Li, L. Zhang, Fabrication of silver-incorporated TiO2 nanotubes and evaluation on its antibacterial activity, Mater Lett 137 (2014) 464-467.

[6] L. S.J, Method for preparing porous titanium and titanium alloy bulk materials, China No200910219978.6 (2011).

[7] R. Aversa, D. Apicella, L. Perillo, R. Sorrentino, F. Zarone, M. Ferrari, A. Apicella, Non-linear elastic three-dimensional finite element analysis on the effect of endocrown material rigidity on alveolar bone remodeling process, Dent Mater 25(5) (2009) 678-90.

[8] M. He, Y. Hou, Y. Jiang, Y. Li, Q. Zou, C. Chen, L. Zhang, W. Yang, Quaternization on polyetheretherketone and its antimicrobial activity, Mater Lett 235 (2019) 242-245.

[9] P. Johansson, S. Barkarmo, M. Hawthan, N. Peruzzi, P. Kjellin, A. Wennerberg, Biomechanical, histological, and computed X-ray tomographic analyses of hydroxyapatite coated PEEK implants in an extended healing model in rabbit, J Biomed Mater Res A 106(5) (2018) 1440-1447.

[10] A. Kumar, W.T. Yap, S.L. Foo, T.K. Lee, Effects of Sterilization Cycles on PEEK for Medical Device Application, Bioengineering 5(1) (2018) 1-10.

[11] L.d. Ruiter, D. Janssen, A. Briscoe, N. Verdonschot, A preclinical numerical assessment of a polyetheretherketone femoral component in total knee arthroplasty during gait, Journal of experimental orthopaedics 4(1) (2017) 3-10.

[12] K. Kang, Y. Koh, J. Son, J.S. Yeom, J.-H. Park, H.-J. Kim, Biomechanical evaluation of pedicle screw fixation system in spinal adjacent levels using polyetheretherketone, carbon-fiber-reinforced polyetheretherketone, and traditional titanium as rod materials, Compos Part B-Eng 130 (2017) 248-256.

[13] W. Guoliang, G. Fanghe, L. Jinlong, D. Yuefei, Individualized reconstructive surgery for skull defects with poly-ether-ether-ketone materials, Chin JMinim Invasive Neurosurg 18(10) (2013) 456-458.

[14] L. Cai, Y. Pan, S. Tang, Q. Li, T. Tang, K. Zheng, A.R. Boccaccini, S. Wei, J. Wei, J. Su, Macromesoporous composites containing PEEK and mesoporous diopside as bone implants: characterization, in vitro mineralization, cytocompatibility, and vascularization potential and osteogenesis in vivo, $\mathrm{J}$ Mater Chem B 5(42) (2017) 8337-8352.

[15] P. Zoidis, I. Papathanasiou, Modified PEEK resin-bonded fixed dental prosthesis as an interim restoration after implant placement, J Prosthet Dent 116(5) (2016) 637-641.

[16] F.B. Torstrick, B.S. Klosterhoff, L.E. Westerlund, K.T. Foley, J. Gochuico, C.S.D. Lee, K. Gall, D.L. Safranski, Impaction durability of porous polyether-ether-ketone (PEEK) and titanium-coated PEEK interbody fusion devices, The spine journal : official journal of the North American Spine Society 18(5) (2018) 857-865. 
[17] D. Botticelli, T. Berglundh, J. Lindhe, Hard-tissue alterations following immediate implant placement in extraction sites, J Clin Periodontol 31(10) (2004) 820-8.

[18] C. Chen, X. Sun, W. Pan, Y. Hou, R. Liu, X. Jiang, L. Zhang, Graphene Oxide-Templated Synthesis of Hydroxyapatite Nanowhiskers To Improve the Mechanical and Osteoblastic Performance of Poly(lactic acid) for Bone Tissue Regeneration, ACS Sustain Chem Eng 6(3) (2018) 3862-3869.

[19] S.R. Shin, C. Zihlmann, M. Akbari, P. Assawes, L. Cheung, K. Zhang, V. Manoharan, Y.S. Zhang, M. Yüksekkaya, K.-t. Wan, M. Nikkhah, M.R. Dokmeci, X.S. Tang, A. Khademhosseini, Reduced Graphene Oxide-GelMA Hybrid Hydrogels as Scaffolds for Cardiac Tissue Engineering, Small 12(27) (2016) 3677-3689.

[20] S. Peng, P. Feng, P. Wu, W. Huang, Y. Yang, W. Guo, C. Gao, C. Shuai, Graphene oxide as an interface phase between polyetheretherketone and hydroxyapatite for tissue engineering scaffolds, Sci Rep-UK 7 (2017) 46604.

[21] X. Wang, J. Jin, M. Song, An investigation of the mechanism of graphene toughening epoxy, Carbon 65 (2013) 324-333.

[22] I. Kelnar, J. Kratochvíl, L. Kaprálková, Z. Špitálsky, M. Ujčič, A. Zhigunov, M. Nevoralová, Effect of Graphene Oxide on Structure and Properties of Impact-Modified Polyamide 6, Polym-Plast Technol 57(9) (2018) 827-835.

[23] K.-H. Nam, J. Yu, N.-H. You, H. Han, B.-C. Ku, Synergistic toughening of polymer nanocomposites by hydrogen-bond assisted three-dimensional network of functionalized graphene oxide and carbon nanotubes, Compos Sci Technol 149 (2017) 228-234.

[24] P. Song, Z. Xu, Y. Wu, Q. Cheng, Q. Guo, H. Wang, Super-tough artificial nacre based on graphene oxide via synergistic interface interactions of $\pi-\pi$ stacking and hydrogen bonding, Carbon 111 (2017) 807-812.

[25] J. Chen, K. Wang, Y. Zhao, Enhanced interfacial interactions of carbon fiber reinforced PEEK composites by regulating PEI and graphene oxide complex sizing at the interface, Compos Sci Technol 154 (2018) 175-186.

[26] T. Tsuda, T. Ogasawara, F. Deng, N. Takeda, Direct measurements of interfacial shear strength of multi-walled carbon nanotube/PEEK composite using a nano-pullout method, Compos Sci Technol 71(10) (2011) 1295-1300.

[27] Wang X, S. M., Toughening of polymers by graphene, (2013).

[28] J.L. Katz, Anisotropy of Young's modulus of bone, Nature 283 (1980) 106.

[29] L.J. Gibson, The mechanical behaviour of cancellous bone, J Biomech 18(5) (1985) 317-328.

[30] Y. Hwang, M. Kim, J. Kim, Improvement of the mechanical properties and thermal conductivity of poly(ether-ether-ketone) with the addition of graphene oxide-carbon nanotube hybrid fillers, Compos Part A-Appl S 55 (2013) 195-202.

[31] F. Li, Y. Hu, X. Hou, X. Hu, D. Jiang, Thermal, mechanical, and tribological properties of short 
carbon fibers/PEEK composites, High Perform Polym 30(6) (2017) 657-666.

[32] T. Ogasawara, T. Tsuda, N. Takeda, Stress-strain behavior of multi-walled carbon nanotube/PEEK composites, Compos Sci Technol 71(2) (2011) 73-78.

[33] X. Hou, Y. Hu, X. Hu, D. Jiang, Poly (ether ether ketone) composites reinforced by graphene oxide and silicon dioxide nanoparticles, High Perform Polym 30(4) (2018) 406-417.

[34] R. Zhu, E. Pan, A.K. Roy, Molecular dynamics study of the stress-strain behavior of carbonnanotube reinforced Epon 862 composites, Mat Sci Eng A-Struct 447(1) (2007) 51-57.

[35] M. Vaezi, C. Black, D.M. Gibbs, R.O. Oreffo, M. Brady, M. Moshrefi-Torbati, S. Yang, Characterization of New PEEK/HA Composites with 3D HA Network Fabricated by Extrusion Freeforming, Molecules 21(6) (2016) 687.

[36] G. Zhang, A.K. Schlarb, S. Tria, O. Elkedim, Tensile and tribological behaviors of PEEK/nano$\mathrm{SiO} 2$ composites compounded using a ball milling technique, Compos Sci Technol 68(15) (2008) 30733080 .

[37] C. von Wilmowsky, E. Vairaktaris, D. Pohle, T. Rechtenwald, R. Lutz, H. Munstedt, G. Koller, M. Schmidt, F.W. Neukam, K.A. Schlegel, E. Nkenke, Effects of bioactive glass and beta-TCP containing three-dimensional laser sintered polyetheretherketone composites on osteoblasts in vitro, J Biomed Mater Res A. 87(4) (2008) 896-902.

[38] Ke Yangchuan, Zheng Yubin, W. Zhongwen., The measurements of crystallinity degree of PEEK, Chinese Journal Of Materials Research 10(2) (1996) 205-209.

[39] J. Chen, Q. Guo, Z. Zhao, X. Shao, X. Wang, C. Duan, Thermal, crystalline, and tribological properties of PEEK/PEI/PES plastics alloys, J Appl Polym Sci 127(3) (2013) 2220-2226.

[40] B. Li, D. Liu, G. Li, X. Yang, Multifold interface and multilevel crack propagation mechanisms of graphene oxide/polyurethane/epoxy membranes interlaminar-toughened carbon fiber-reinforced polymer composites, J Mater Sci 53(23) (2018) 15939-15951.

[41] B. Mayoral, E. Harkin-Jones, P.N. Khanam, M. AlMaadeed, M. Ouederni, A. Hamilton, D. Sun, Melt processing and characterisation of polyamide 6/graphene nanoplatelet composites, RSC Adv 5(65) (2015) 52395-52409.

[42] M.I. Martín, F. Rodríguez-Lence, A. Güemes, A. Fernández-López, L.A. Pérez-Maqueda, A. Perejón, On the determination of thermal degradation effects and detection techniques for thermoplastic composites obtained by automatic lamination, Compos Part A-Appl S 111 (2018) 23-32.

[43] M. Remanan, M. Kannan, R.S. Rao, S. Bhowmik, L. Varshney, M. Abraham, K. Jayanarayanan, Microstructure Development, Wear Characteristics and Kinetics of Thermal Decomposition of Hybrid Nanocomposites Based on Poly Aryl Ether Ketone, Boron Carbide and Multi Walled Carbon Nanotubes, J Inorg Organomet P 27(6) (2017) 1649-1663.

[44] L. Ouyang, Y. Deng, L. Yang, X. Shi, T. Dong, Y. Tai, W. Yang, Z.G. Chen, Graphene-OxideDecorated Microporous Polyetheretherketone with Superior Antibacterial Capability and In Vitro Osteogenesis for Orthopedic Implant, Macromol Biosci 18(6) (2018) e1800036. 
[45] L. Ouyang, M. Qi, S. Wang, S. Tu, B. Li, Y. Deng, W. Yang, Osteogenesis and Antibacterial Activity of Graphene Oxide and Dexamethasone Coatings on Porous Polyetheretherketone via PolydopamineAssisted Chemistry, Coatings 8(6) (2018) 203.

[46] F. Awaja, M. Tripathi, T.-T. Wong, T. O'Brien, G. Speranza, The chemistry and topography of stabilized and functionalized graphene oxide coatings, Plasma Process Polym 15(10) (2018) 1800084.

[47] F. Colangelo, A. Pitanti, V. Mišeikis, C. Coletti, P. Pingue, D. Pisignano, F. Beltram, A. Tredicucci, S. Roddaro, Controlling local deformation in graphene using micrometric polymeric actuators, 2D Mater 5(4) (2018) 045032.

[48] E. Lee, J. Baek, J.S. Park, J. Kim, J.M. Yuk, S. Jeon, Effect of nucleation density on the crystallinity of graphene grown from mobile hot-wire-assisted CVD, 2D Mater 6(1) (2018) 011001.

[49] P. DiAntonio, B.E. Vugmeister, J. Toulouse, L.A. Boatner, Polar fluctuations and first-order Raman scattering in highly polarizable crystals with off-center Li and Nb ions, Phys Rev B 47(10) (1993) 56295637.

[50] N. Nakatsuka, M.M. Hasani-Sadrabadi, K.M. Cheung, T.D. Young, G. Bahlakeh, A. Moshaverinia, P.S. Weiss, A.M. Andrews, Polyserotonin Nanoparticles as Multifunctional Materials for Biomedical Applications, ACS Nano 12(5) (2018) 4761-4774.

[51] L. Deng, Y. Deng, K. Xie, AgNPs-decorated 3D printed PEEK implant for infection control and bone repair, Colloid Surface B 160 (2017) 483-492.

[52] I.A. Vacchi, J. Raya, A. Bianco, C. Ménard-Moyon, Controlled derivatization of hydroxyl groups of graphene oxide in mild conditions, 2D Mater 5(3) (2018) 035037.

[53] A.R. Khoei, M.S. Khorrami, Mechanical properties of graphene oxide: A molecular dynamics study, Fullerenes, Fuller Nanotub Car N 24(9) (2016) 594-603.

[54] F.S. Kim, G. Ren, S.A. Jenekhe, One-Dimensional Nanostructures of $\pi$-Conjugated Molecular Systems: Assembly, Properties, and Applications from Photovoltaics, Sensors, and Nanophotonics to Nanoelectronics, Chem Mater 23(3) (2011) 682-732.

[55] C. Chen, X. Zhu, B. Chen, Covalently cross-linked graphene oxide aerogel with stable structure for high-efficiency water purification, Chem Eng J 354 (2018) 896-904. 